\title{
The effect of acrylamide on the peripheral nervous system of the baboon
}

\author{
ANTHONY HOPKINS \\ From The Institute of Neurology, Queen Square, London
}

SUMMARY In the baboon, acrylamide produces a clinical illness characterized by weakness and ataxia of the limbs, weakness of bulbar muscles, and finally tetraplegia. Histological examination shows extensive involvement of peripheral nerves, the main histological change being a Wallerian type of degeneration affecting the distal ends of the largest diameter nerve fibres. The phenomenon of 'dying back' has been demonstrated in single teased fibres. Changes also occur in the paranodal myelin; these are not necessarily associated with degeneration of the axon, since intercalated segments and extension of myelin from neighbouring internodes are present in recovering animals. Demyelination of whole internodes is rare. Paranodal changes may be found a few millimetres proximal to complete degeneration, but may also occur on fibres which are otherwise normal in the length examined. The mechanism of the paranodal changes is uncertain, but they may indicate a secondary response of the Schwann cell to a primary change in the axon.

Acrylamide $\left(\mathrm{CH}_{2}=\mathrm{CH} . \mathrm{CONH}_{2}\right)$ is used to make a non-toxic polymer which improves dry strength in manufactured paper and chipboard. It is also used as a grouting agent to waterproof tunnels and foundations, and by biochemists as the stationary phase during the electrophoretic separation of proteins. Acrylamide poisoning has been described in workers employed in the manufacture of the polymer (Garland and Patterson, 1967), and Fullerton (1969) has studied the electrophysiological changes in some of these patients. The patients developed paraesthesiae and marked ataxia, due, at least in part, to impairment of postural sensation. Tendon reflexes were absent and there was a marked increase in sweating of the extremities. Most patients made a good recovery on withdrawal from exposure to acrylamide.

Kuperman (1958) studied the effects of acute and chronic administration of acrylamide on the cat. A single injection of 75 to $1,000 \mathrm{mg} / \mathrm{kg}$ produced ataxia, tremor, weakness, vomiting and defaecation, and periodic convulsions. With subacute doses, postural and motor incoordination developed. McCollister, Oyen, and Rowe (1964) described experimental acrylamide intoxication of rats, cats, and monkeys, producing a paralytic illness. No changes were found in the central nervous system in either study. However, these authors did not examine the peripheral nerves electrophysiologically or histologically. Fullerton and Barnes (1966) studied acrylamide intoxication in the rat, and found a Wallerian type of degeneration affecting fibres of large diameter. Prineas (1969b) has recently reported the electron microscopic changes in acrylamideintoxicated cats.

The present study is concerned with the effect of acrylamide on the peripheral nervous system of the baboon (Papio hamadryas). Clinical observations were supplemented by nerve biopsies at different stages of the illness. Some animals were killed for detailed histological study while receiving acrylamide or shortly after; other animals were allowed to recover for up to two years. Repeated electrophysiological studies were carried out on the same animals and will be the subject of a separate report.

\section{METHODS}

Five female baboons (Papio hamadryas) weighing $12 \cdot 1$ to $15.4 \mathrm{~kg}$, and two male Papio hamadryas weighing 9.4 and $10.3 \mathrm{~kg}$ were studied. All the females showed the cyclical changes of the skin associated with sexual maturity, but the males were not fully grown as judged by the length and colour of their cape. Their ages were thought to be between 4 and 6 years. The animals were fed on a solid pellet diet (M.R.C. 41B), but daily fruit, cabbage, or carrot was given in addition to this. They also received monthly injections of $1,000 \mu \mathrm{g}$ of vitamin $B_{12}$ (Glaxo Laboratories).

Acrylamide was administered as a $10 \%$ solution in water. The dose was 10,15 , or $20 \mathrm{mg} / \mathrm{kg}$, and calculated 
on the initial weight of the animal. The solution was injected into an orange or banana as described by McCollister et al. (1964). The animals ate the fruit readily, but in some severely affected animals it became necessary towards the end of the illness to give acrylamide by injection or by gastric tube, as the animals were too weak to eat the fruit. Milk or Complan (Glaxo) was given at these times.

Detailed clinical examinations of unanaesthetized animals were not attempted, reliance being placed upon daily observation of the animals within their cages. In order to allow comparisons between different animals and different stages of the disease, the animals were filmed at intervals both in their cages and while moving freely outside them.

Tendon reflexes were examined a few minutes after the intramuscular injection of phencyclidine $2 \mathrm{mg} / \mathrm{kg}$ (Sernylan, Parke-Davis and Co.) and promazine $1 \mathrm{mg} / \mathrm{kg}$ (Sparine, John Wyeth). In healthy animals, the knee and triceps jerks were easily obtained at this level of anaesthesia.

HISTOLOGICAL TECHNIQUE When biopsy specimens were required, short lengths of sural or radial nerves were removed under aseptic conditions, the animals being anaesthetized as above, with the addition of intravenous pentobarbitone sodium $3 \mathrm{mg} / \mathrm{kg}$ (Nembutal, Abbott Laboratories). No tourniquet was used. One portion of nerve was attached to a card, care being taken to mark the proximal end, and fixed in $10 \%$ formol saline. Part of this length was stained with $1 \%$ osmium tetroxide, and then single fibres were examined by teasing in a pool of glycerine (Thomas, 1955). Another part was impregnated with silver, and stained with luxol fast blue, and cresyl violet (McDonald, 1963) to show the axon and neurokeratin network. A further length was fixed in Flemming's solution, and transverse sections were stained with Kultschitsky's haematoxylin by a modified Weigert method (Gutmann and Sanders, 1943). At necropsy other less readily accessible nerves were removed, fixed, and stained as above.

Sections stained with Kultschitsky's haematoxylin were photographed at a magnification of $\times 250$, and printed at a further fourfold enlargement. Fibres in the resulting montage were matched against holes of 2 to $20 \mathrm{~mm}$ diameter in a Perspex disc (Swallow, 1966), using a mechanical counter. When counting the diameters of fibres from animals intoxicated with acrylamide, the presence of swollen degenerating fibres and of myelin debris sometimes made measurement difficult. It was decided to include every myelin ring with a central core of axoplasm, even though it was realized that in this way a number of degenerating fibres might be included.

Quantitative studies were made on the sural nerve $4 \mathrm{~cm}$ above the lateral malleolus, and on the digital nerve on the lateral side of the proximal phalanx of the third finger. As branching was frequent at these levels, it was necessary to calculate a figure for the density of fibres per unit area. For the calculation of this figure, between 750 and 1,000 fibres were measured from a fascicle chosen at random. The area of the fascicle was then calculated as described by Swallow (1966). In one sural nerve all fascicles were measured (a total of more than 3,000 fibres), and the distribution of fibre diameters did not differ significantly from that of the first 750. Quantitative studies were also made on the nerve to the extensor digitorum brevis muscle at its origin from the anterior tibial nerve. All fibres in this nerve could be included as there was no branching at this site.

The lengths and diameters of internodal segments of single teased fibres mounted in balsam were measured at magnification of $\times 100$ and $\times 1,000$ using a graduated eyepiece.

\section{RESULTS}

a. DOSAGE SCHEDULeS The first baboon (B18) to be given acrylamide received $20 \mathrm{mg} / \mathrm{kg} /$ day, a dose thought to be appropriate from the experience of McCollister, Oyen, and Rowe (1964). This animal developed clinical signs more rapidly than had been expected, and in the remaining animals the dose was reduced to $15 \mathrm{mg} / \mathrm{kg} / \mathrm{day}$ (B15) and to $10 \mathrm{mg} / \mathrm{kg} / \mathrm{day}$ (B16, 17, 19, 23, 25). These dosage schedules must in any case be regarded as approximate as it was not possible to ensure that the animals ate all the fruit into which the acrylamide had been injected. Baboon 16 was notably reluctant to do so.

b. CLINICAL ILLNESS The main features of the illnes produced by acrylamide are summarized in Table 1 . (For details of individual animals, see Hopkins, $\mathbb{D}$ 1968.) Ataxia and weakness of the hindquarters were early signs of intoxication, first noticed when the animal was allowed to run free, and later wher. attempting to stand on the hind legs alone. Clumsi ness of the hands was usually the next sign, although the upper limbs remained relatively strong. Ataxia

\section{TABLE 1}

SUMMARY OF MAIN FEATURES OF CLINICAL ILLNESS OF SEVEN BABOONS INTOXICATED BY ACRYLAMIDE*

\begin{tabular}{|c|c|c|c|c|c|c|c|}
\hline $\begin{array}{c}\text { Baboon } \\
\text { Dose }(m g / k g / d a y)\end{array}$ & $\begin{array}{l}18 \\
20\end{array}$ & $\begin{array}{l}15 \\
15\end{array}$ & $\begin{array}{l}16 \\
10\end{array}$ & $\begin{array}{l}17 \\
10\end{array}$ & $\begin{array}{l}19 \\
10\end{array}$ & $\begin{array}{l}23 \\
10\end{array}$ & $\begin{array}{l}25 \\
10\end{array}$ \\
\hline $\begin{array}{l}\text { Duration of } \\
\text { intoxication } \\
\text { Onset of hindlimb }\end{array}$ & 29 & 94 & 192 & 115 & 137 & 89 & 99 \\
\hline $\begin{array}{l}\text { signs } \\
\text { Onset of forelimb }\end{array}$ & 16 & 42 & 97 & 42 & 56 & 82 & 68 \\
\hline $\begin{array}{l}\text { signs } \\
\text { Onset of jaw }\end{array}$ & 28 & 73 & 147 & 81 & 96 & 61 & 90 \\
\hline $\begin{array}{l}\text { weakness } \\
\text { Onset of aphonia } \\
\text { Absence of knee jerks } \\
\text { Unable to sit up on }\end{array}$ & $\begin{array}{l}28 \\
23 \\
\text { Not t }\end{array}$ & $\begin{array}{c}81 \\
81 \\
\text { tested }\end{array}$ & $\begin{array}{l}167 \\
147 \\
165\end{array}$ & $\begin{array}{r}73 \\
96 \\
164\end{array}$ & $\begin{array}{r}110 \\
75 \\
91\end{array}$ & $\begin{array}{l}\text { None } \\
\text { Dysphonia } \\
91\end{array}$ & $\begin{array}{l}97 \\
90 \\
97\end{array}$ \\
\hline $\begin{array}{l}\text { day } \\
\text { Commencement of }\end{array}$ & Able & 95 & 191 & Able & 138 & Able & 97 \\
\hline $\begin{array}{l}\text { recovery } \\
\text { Recovery complete }\end{array}$ & $\begin{array}{l}34 \\
91\end{array}$ & $\begin{array}{r}96 \\
364 \\
970\end{array}$ & - & $\begin{array}{l}127 \\
253\end{array}$ & 139 & $\begin{array}{r}91 \\
171\end{array}$ & 109 \\
\hline Day killed & 93 & 870 & 192 & 541 & 154 & 398 & 118 \\
\hline
\end{tabular}

* The numbers tabulated represent days after beginning administration of acrylamide. 
increased rapidly so that the animal could not lift either hand from the floor of the cage without falling sideways. At this stage food was usually taken from the hopper with the mouth, but if a hand were used, it was grossly ataxic as it approached the mouth. Sometimes a piece of fruit would be dropped, but the hand would continue towards the mouth as if the animal were unaware that this had happened, implying some sensory loss. At no stage, however, could any failure to feel pinprick be demonstrated. The quadriceps and triceps tendon reflexes were abolished in all animals tested atout eight weeks after the earliest clinical signs.

At about the time that the upper limbs were affected, weakness of the jaw and facial muscles became obvious. The animal had difficulty in biting through an apple, and in emptying its cheek pouches. No weakness of respiratory muscles was observed, but in all animals the bark became hoarser and softer, and all except B23 eventually became silent.

Intoxication of B15, B16, B23, and B25 was continued until weakness and ataxia of the limbs were such that the animal was unable to rise from a lying position. Weakness of facial and jaw muscles was so severe in three of these animals that feeding by gastric tube was required.

Loss of weight was another major feature of the illness, the loss ranging from 17 to $45 \%$. As much as $20 \%$ of the initial weight could be lost at a time when the animal was still active. No impairment of sphincter control or of the sexual cycles was apparent. The appetite remained normal until the animals were severely paralysed.

One baboon was killed during the administration of acrylamide, while severely paralysed, and two were killed within three weeks of stopping it. Three were allowed to recover for periods of up to 776 days (Table 2). On stopping acrylamide, it was noticeable that deterioration continued for two to three days. The physical signs then remained static for

TABLE 2

DAYS OF EXAMINATION OF NERVES

\begin{tabular}{ccccc}
\hline Baboon & $\begin{array}{c}\text { Day acrylamide } \\
\text { stopped }\end{array}$ & \multicolumn{2}{c}{ Day of biopsy } & Day of necropsy \\
\cline { 3 - 4 } & & Sural & Radial & \\
\hline 15 & 94 & 127 & 206 & 870 \\
16 & 192 & 141 & & 192 \\
17 & 115 & 159 & & \\
18 & 29 & & 232 & 541 \\
19 & 137 & 73 & 493 & 93 \\
23 & 89 & 108 & 257 & 154 \\
25 & 99 & 41 & & 118 \\
\hline
\end{tabular}

the next two to three days, after which improvement began. The early stages of recovery were rapid. For example, an animal reduced to a state in which it was unable to swallow or sit up, would be able to sit up after two days and to take fruit and water. Weakness and ataxia of the limbs persisted for a much longer period after stopping acrylamide. Clumsiness of the hands was seen to a diminishing extent for 92 days in B23, 138 days in B17, and 270 days in B15. At the end of this time the hind limbs of these animals were also clinically normal except that B15 had flexion deformities of $10^{\circ}$ at knee and hip.

c. Histological OBSERVATIONS Peripheral nerves were biopsied on four occasions during the period of intoxication, and on eight occasions between two and 70 weeks after stopping acrylamide (Table 2). Animals were killed either during the illness (B16), within nine weeks (B18, B19, B25), or after a prolonged period of recovery (B15, B17, B23).

Longitudinal sections impregnated with silver left no doubt that, by light microscopy, the main pathological changes were of the Wallerian type (Fig. 1). Fragmentation of the axon, clumping of the neurokeratin network, and the formation of digestion chambers are illustrated, and were found in all the biopsy or necropsy material taken during or shortly after the administration of acrylamide.

Transverse sections stained for myelin were used to estimate the extent of damage at different sites in the peripheral nervous system. Motor nerves were affected as well as purely sensory nerves. Figure 2 shows a marked reduction in the numbers of myelinated fibres in the nerve to extensor digitorum brevis and a digital nerve from two animals.

Inspection of moderately affected nerves suggested that fibres of large diameter were predominantly affected. It was sometimes difficult to measure the diameters of fibres in the acute stage of degeneration, because measurements were disturbed by the presence of swollen degenerating fibres. However three sural nerves were obtained in which the overall picture was neither complicated by the swelling of degenerating fibres, nor by the presence of small regenerating fibres. These nerves were obtained 41, 108 and 154 days after starting acrylamide; in the last two cases acrylamide had been stopped for 17 and 19 days. The results of measurements of fibre diameter on these three nerves are shown in Fig. 3 and Table 3. The results from a control baboon are shown for comparison. It can be seen that the proportion of myelinated fibres of large diameter decreases with increasing duration of intoxication. A relative reduction of large diameter fibres was also found in the digital nerves of three 


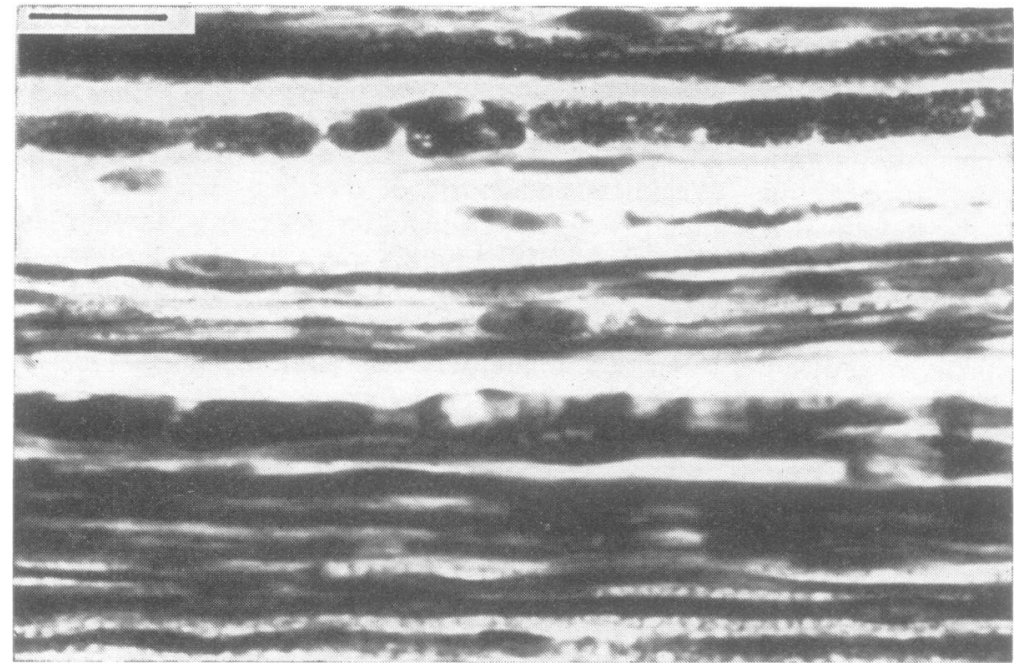

FIG. 1. Longitudinal section of 3 rd digital nerve of $B 25$, 118 days after beginning acrylamide. Silver, luxol-fast blue and cresyl violet. Scale$100 \mu$.

TABLE 3

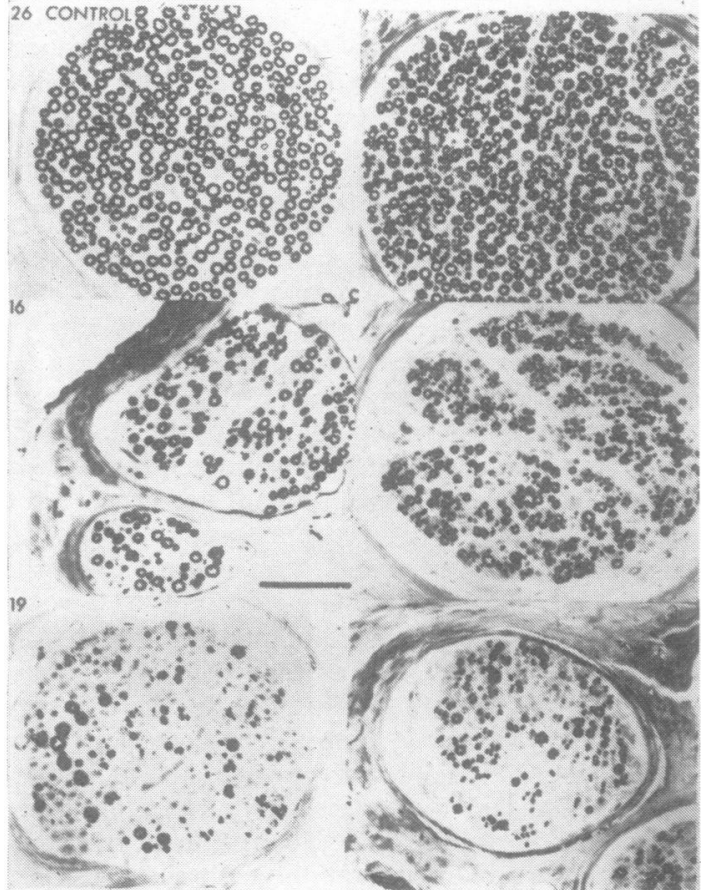

FIG. 2. Transverse section of the nerve to extensor digitorum brevis (left) and of the 3rd digital nerve of the hand (right) in a control baboon (top), in B16 (middle) and B19 (bottom). Kultschitsky's haematoxylin. Scale$100 \mu$.
DENSITY OF MYELINATED FIBRES IN SURAL AND DIGITAL NERVES, EXPRESSED AS THOUSAND FIBRES PER SQ MM

\begin{tabular}{|c|c|c|c|}
\hline & & Diameter $2-8 \mu$ & $\begin{array}{c}\text { Diameter } 9 \mu \\
\text { or greater }\end{array}$ \\
\hline $\begin{array}{c}\text { Sural } n \\
\text { Control } \\
\text { B26 }\end{array}$ & & $2 \cdot 78$ & $3 \cdot 32$ \\
\hline $\begin{array}{c}\text { Intoxica } \\
\text { B25 } \\
\text { B23 } \\
\text { B19 }\end{array}$ & $\begin{array}{l}\text { Day } 41 \\
\text { Day } 108 \\
\text { Day } 154\end{array}$ & $\begin{array}{l}2 \cdot 76 \\
2 \cdot 87 \\
2 \cdot 86\end{array}$ & $\begin{array}{l}3.09 \\
1.11 \\
0.83\end{array}$ \\
\hline $\begin{array}{c}\text { Digital } \\
\text { Control } \\
\text { B24 } \\
\text { B26 }\end{array}$ & the hand & $\begin{array}{l}3 \cdot 58 \\
3 \cdot 52\end{array}$ & $\begin{array}{l}2 \cdot 54 \\
3 \cdot 48\end{array}$ \\
\hline $\begin{array}{c}\text { Intoxica } \\
\text { B25 } \\
\text { B19 } \\
\text { B16 }\end{array}$ & $\begin{array}{l}\text { Day } 118 \\
\text { Day } 154 \\
\text { Day } 192\end{array}$ & $\begin{array}{l}2 \cdot 80 \\
1 \cdot 69 \\
2 \cdot 24\end{array}$ & $\begin{array}{l}1 \cdot 16 \\
0 \cdot 18 \\
0.47\end{array}$ \\
\hline
\end{tabular}

animals killed during or shortly after the administration of acrylamide (Table 3 ).

From necropsy studies it was clear that the long nerves to distal muscles were more severely affected than those to proximal muscles. This is illustrated by Fig. 4, which shows the nerve to biceps femoris muscle, and the nerve to the extensor digitorum brevis muscle of B19, after the administration of acrylamide for 137 days. It was also clear that nerve fibres passing to the extremities were affected only in their distal parts, the sciatic nerve and spinal roots being normal in animals which showed a 

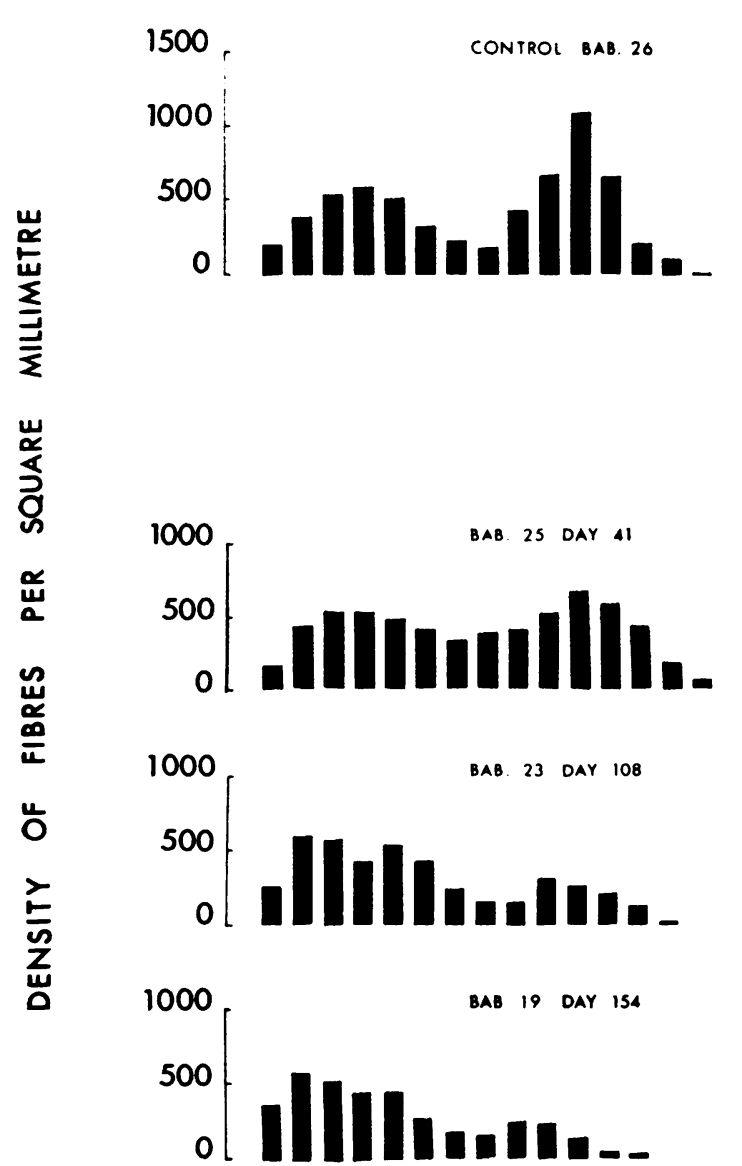

$\begin{array}{llllllll}2 & 4 & 6 & 8 & 10 & 12 & 14 & 16\end{array}$

\section{DIAMETER $(\mu)$}

FIG. 3. Distribution of diameters of myelinated fibres in the sural nerves (ankle) of three baboons during or shortly after intoxication with acrylamide, and of one control baboon.

severe loss of myelinated fibres in the nerves to the muscles of the feet. The predominantly distal involvement of long nerves was confirmed when the recurrent largyngeal nerve was studied. As an example, Fig. 5 shows the left recurrent laryngeal nerve of B25. It can be seen that nearly all the myelinated fibres have degenerated at the level of the larynx whereas many intact fibres are present at the level of the ligamentum arteriosum. A similar difference between the proximal and distal ends of the left recurrent laryngeal nerve was present in B16 and B19.

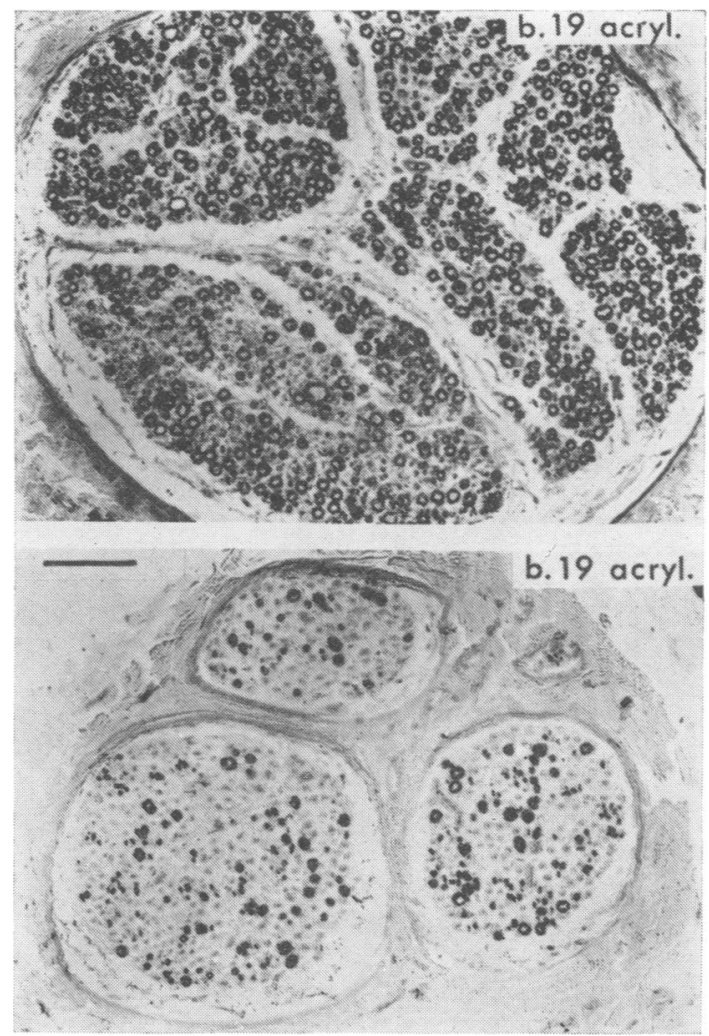

FIG. 4. Transverse sections of the nerve to biceps femoris (above) and of the nerve to extensor digitorum brevis (below), of B19, 154 days after beginning acrylamide. Kultschitsky's haematoxylin. Scale-100 $\mu$.

When fibres from a degenerating nerve were being teased apart, it was sometimes possible to follow single fibres through a transitional zone between apparently normal and degenerating myelin. Figure 6 shows such a fibre followed for 4 to $5 \mathrm{~mm}$. Successive lengths are mounted below each other. In the upper half of the figure three apparently normal nodes of Ranvier are indicated by arrows. The myelin of these internodal segments appears normal. Distal to this the myelin becomes swollen and irregular, and large gaps appear so that the original nodes of Ranvier are not identifiable. Further distally, degeneration has reached an advanced stage.

In any one nerve trunk the centripetal spread of degeneration varied between one fibre and another. Thus, while the sciatic nerve in the thigh might be normal, and the sural nerve, digital nerves, and the nerve to the extensor digitorum brevis muscle severely degenerated, the intermediate zone between knee and ankle would contain a mixture of intact 

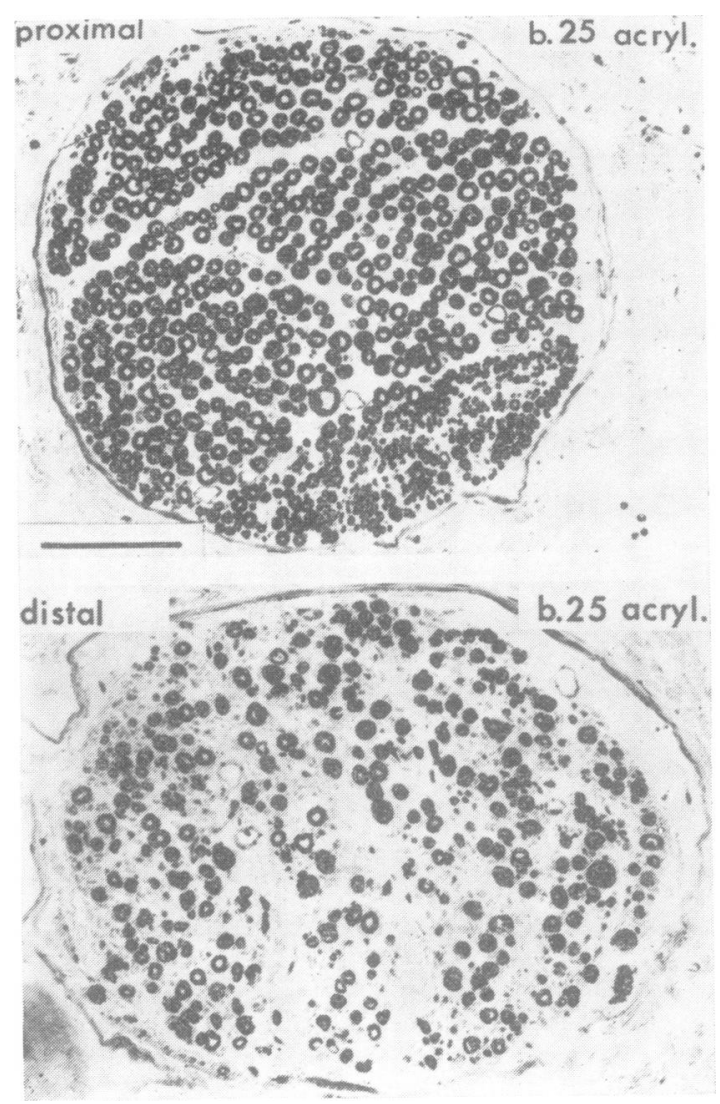

FIG. 5. Transverse sections of the left recurrent laryngeal nerve of $B 25,118$ days after beginning acrylamide. The proximal level is at the ligamentum arteriosum, the distal at the larynx. Kultschitsky's haematoxylin. Scale-100 $\mu$.

fibres, completely degenerated fibres, and fibres showing degeneration only in their distal parts. In the short lengths obtained by teasing single fibres apart, the last named group were difficult to find. In all, only 10 fibres showing changes similar to those seen in Fig. 6 were found out of many hundreds examined.

REGENERATION Table 2 shows the times at which nerves were examined in animals at various intervals during recovery. Histological examination of nerves to muscles which had previously been clinically paralysed and completely denervated on electrical testing, revealed after a few months large numbers of fine myelinated fibres which were believed to be regenerating. At this stage direct evidence of regeneration could be obtained only if such a fibre was teased in continuity with its proximal unaffected portion. An example is shown in Fig. 7. Successive lengths of a single fibre have been mounted below each other for a distance of $8 \mathrm{~mm}$. At the proximal end two apparently normal nodes of Ranvier are seen ( $a$ and $b)$. Then follow two short remyelinated segments (c and d), of a type which will be further discussed below. Distal to these is a long succession of thinly myelinated segments which are presumed to be regenerating. The internodal length for the distance (a) to (b) is $1.03 \mathrm{~mm}$, and the diameter of the fibre at this point is approximately $11 \mu$. The length of the regenerating internodes varies between 0.26 and $0.59 \mathrm{~mm}$, with a mean of $0.36 \mathrm{~mm}$.

It has already been mentioned that junctional zones between normal and degenerating myelin were difficult to find in single fibres obtained by teasing. The same difficulty existed in finding junctions between normal and regenerating segments. In all only eight examples were seen among the several hundred fibres examined.

When the junction between the normal and regenerating segments is not seen, the assumption that a fibre has regenerated may be made if the internodes are inappropriately short for a fibre of that diameter (Vizozo and Young, 1948). Figure 8 shows the relationship between internodal length $\stackrel{\mathbb{P}}{\stackrel{\oplus}{\circ}}$ and fibre diameter for fibres teased from the nerveo to the extensor digitorum brevis muscle of two control animals (Fig. 8a and b) and from B15o (Fig. 8c) 776 days after the last dose of acrylamide The data has been presented in the manner of Fullerton, Gilliatt, Lascelles, and Morgan-Hughes(1965). It can be seen that a fibre $9 \mu$ in diameter from the control animals is likely to have a mean internodal length of approximately $0.85 \mathrm{~mm}$, whereas a fibre $9 \mu$ diameter from B15 has a mean internodal length of approximately $0.4 \mathrm{~mm}$. It seems reasonable to assume that such a fibre has regenerated.

In addition to the examination of single fibres, the recovery of fibre diameter in transverse sections was studied. For this purpose, measurements of diameter were made on the nerve to the extensor digitorum brevis muscle from the three animals which had been allowed to recover for long periods $(B 15,17,23)$. Since this is a small nerve which does not branch for some millimetres, all fibres in the nerve were measured. Measurements of diameter were also made on digital nerves from the same animals but, since these nerves branch extensively, total fibre counts were not thought to be meaningful. Accordingly, a sample of the fibre population was measured for each nerve, from which fibre density could be calculated. The results are shown in Fig. 9 in which the histograms may be compared with 


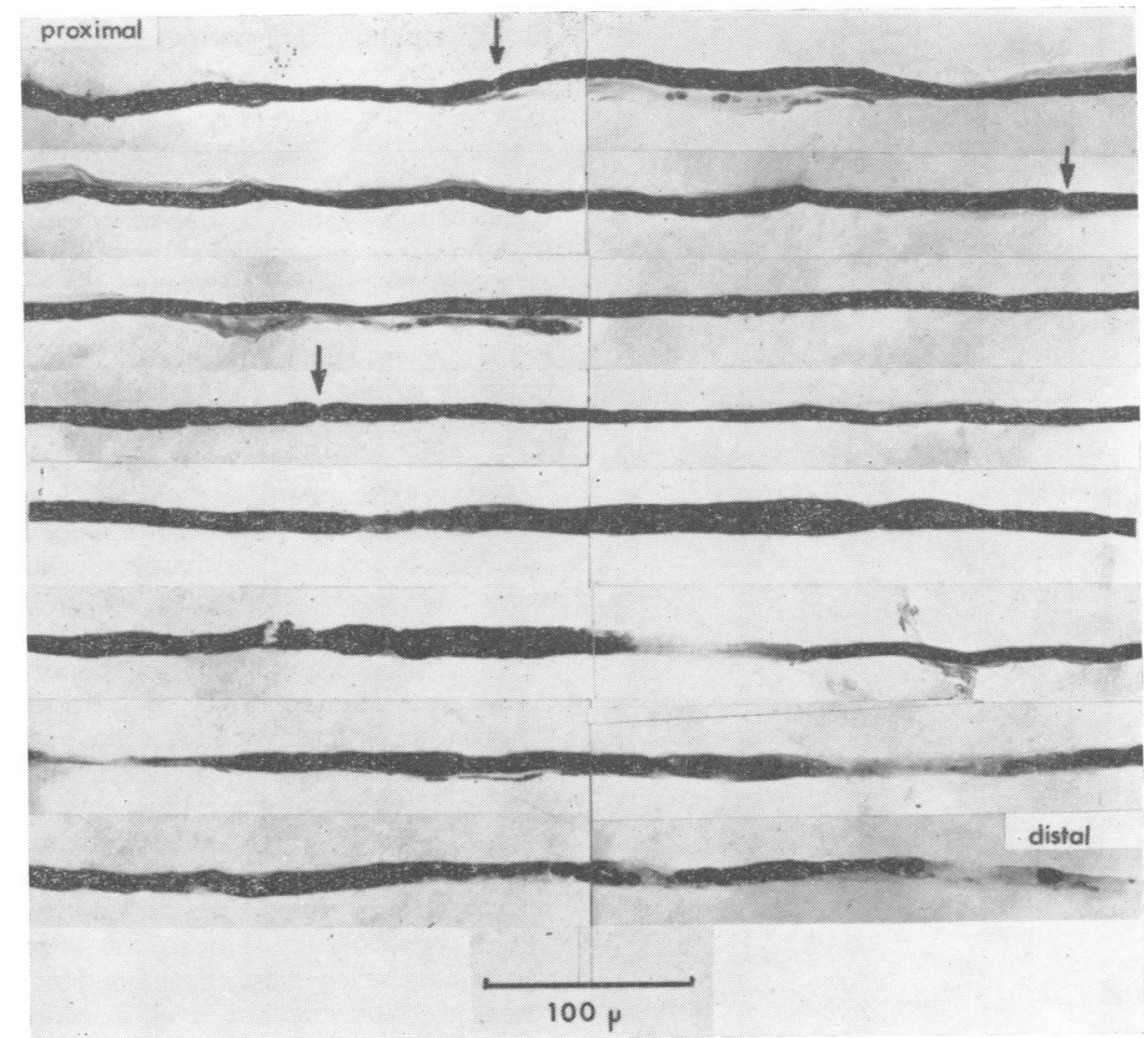

FIG. 6. Single fibre from the nerve to extensor digitorum brevis of $\mathrm{B} 25,118$ days after beginning acrylamide. Successive lengths of the fibre are mounted below each other. Arrows indicate nodes of Ranvier. Osmium tetroxide.

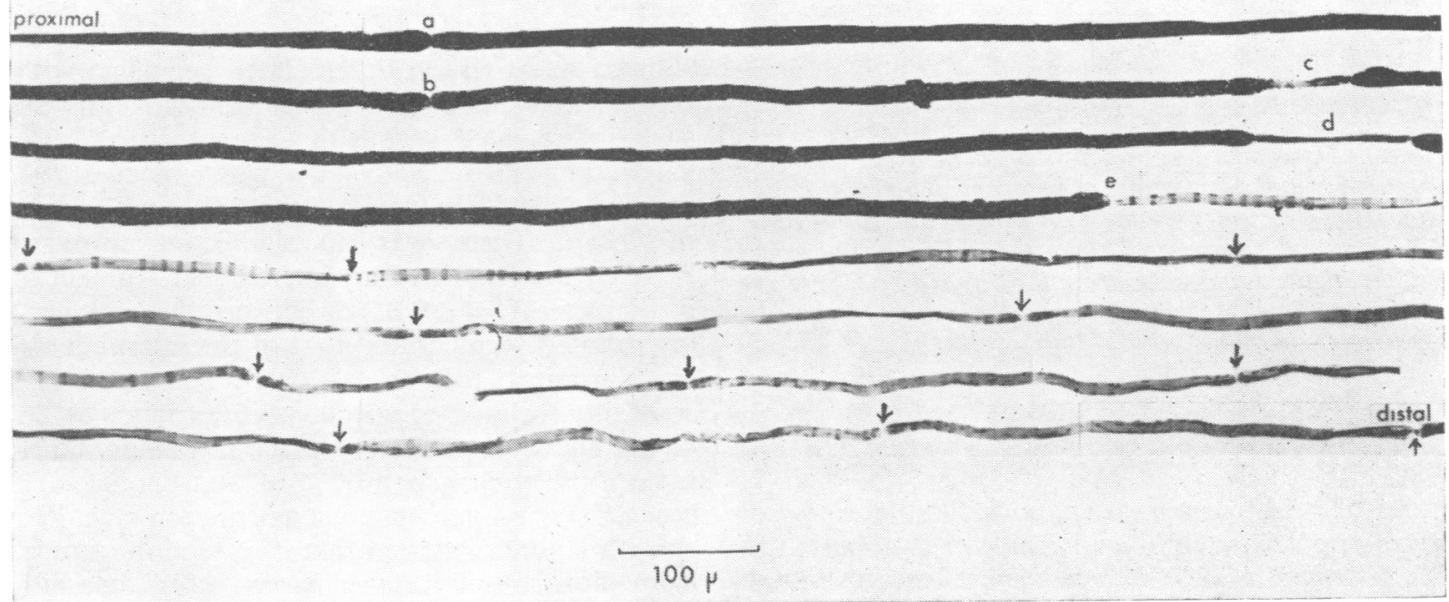

FIG. 7. Single fibre from the nerve to the medial head of gastrocnemius of B17, 426 days after stopping acrylamide. Successive lengths of the fibre are mounted below each other. Letters a-e are discussed in the text. Osmium tetroxide. 

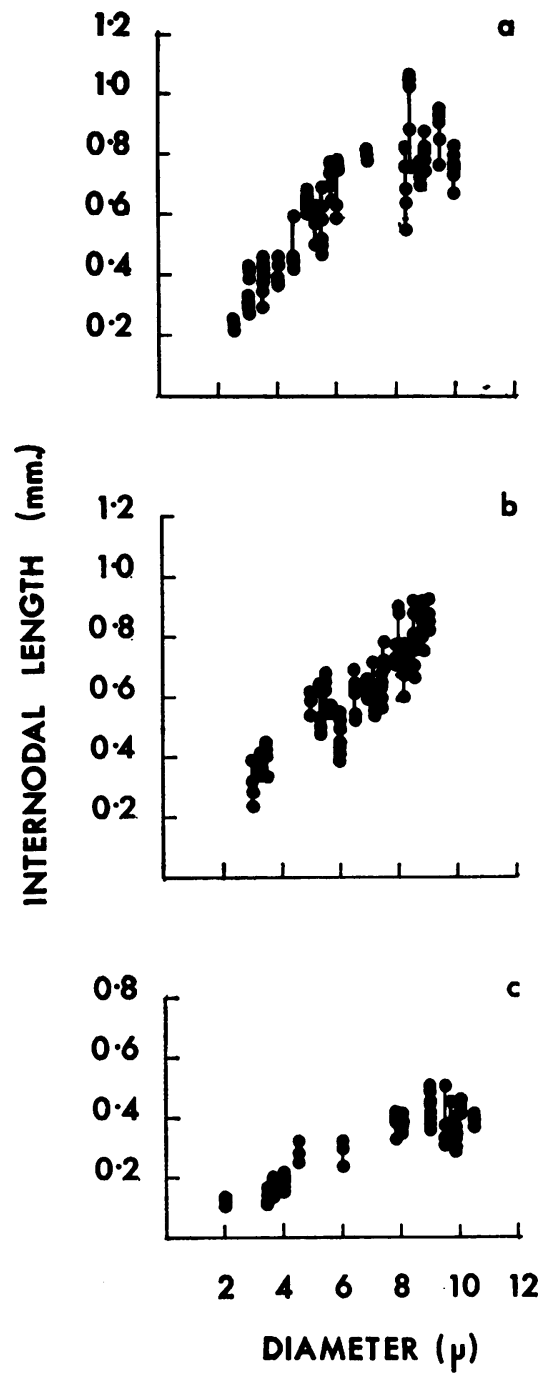

FIG. 8. Internodal length and fibre diameter in the nerve to extensor digitorum brevis of two control baboons (a and b) and of B15, after 94 days on acrylamide, followed by 776 days of recovery. Values for different internodal lengths of the same fibre are joined by a line. These are plotted against the diameter of the widest internodal segment of that fibre.

those of healthy animals. A considerable excess of fibres approximately $6 \mu$ in diameter is apparent in the histograms of B23 (309 days after poisoning), whereas in B17 and B15 (426 and 776 days after poisoning) there is an excess of 8 to $9 \mu$ fibres. This difference suggests that the diameter of regenerated fibres was continuing to increase during the second year of recovery.

REMYELINATION In fibres such as that illustrated in Fig. 7 , in which the junction between normal and 0 regenerating myelin is shown, it was usual to find that defects had occurred in the myelin in the regions of the nodes just proximal to the upper level of degeneration. This has resulted, in the fibre shown in Fig. 7, in two short intercalated segments similar to those described by Lubińska (1961) immediately above a nerve crush. Sometimes as many as three intercalated segments were seen in this situation.

As has been mentioned earlier, junctional zones between normal and regenerating myelin were found relatively infrequently in recovering animals. Intercalated segments were more commonly seen with apparently normal myelin proximal and distal to them. As single fibres could not be followed for more than about $10 \mathrm{~mm}$ it was not possible to decide whether such intercalated segments occurred only on fibres with regeneration of their distal parts, or whether they could occur independently of this. In general, however, intercalated segments were absent in the lumbar roots and rare in proximal nerves They were also rare at the extremities of the limbo where most of the fibres had degenerated an regenerated. They were most frequent in specimens taken at an intermediate level, in which some fibres $\mathbb{0}$ were unaffected, and others had undergone degenerso tion and regeneration. Even at this level intercalate segments were not common, affecting not moro than 10 to $20 \%$ of fibres.

Remyelination was studied quantitatively in the nerve to the medial head of the gastrocnemius muscle of B15, which had been allowed to recover for the longest time (776 days). Fibres were selected which showed one or more intercalated segments with a recognizable node of Ranvier at each end. Sixty such intercalated segments were measured. Their length ranged from 60 to $460 \mu$, with a mean of $262 \mu$, and their diameter from 5.5 to $13.0 \mu$, with a mean of $9.2 \mu$. There was no significant correlation between the length of an intercalated segment and its diameter $(r=+0 \cdot 21)$ or between the length of an intercalated segment and that of the internodal segment proximal to it $(r=+0.07)$. The diameters of some intercalated segments were as large as $\mathbf{8 0} \%$ of the diameter of the preceding internode, but the majority were less than $60 \%$ of that diameter. The longest single intercalated segment seen was $460 \mu$, ᄋ and it may be suggested that if retraction of myelin from the node of Ranvier exceeds this, then either two Schwann cells are intercalated, or the whole internode breaks down and remyelination of the segment takes place with two, three, or four Schwann 

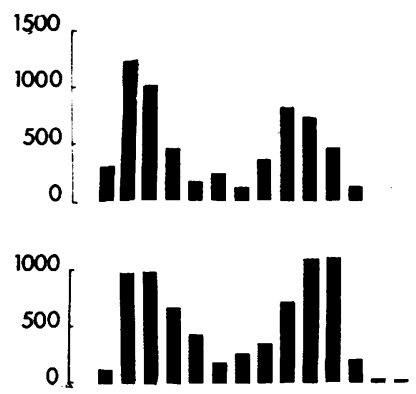

CONTROL

ANIMALS

24

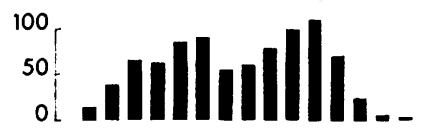

26

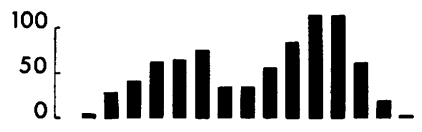

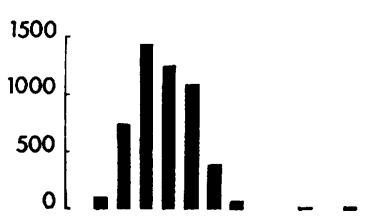
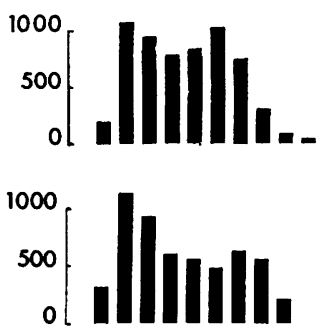

$\begin{array}{llllllll}2 & 4 & 6 & 8 & 10 & 12 & 14 & 16\end{array}$

DIAMETER $(\mu)$
RECOVERING
ANIMALS

23

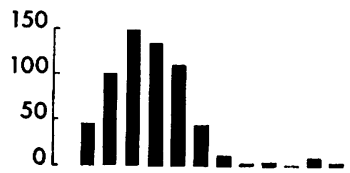

17

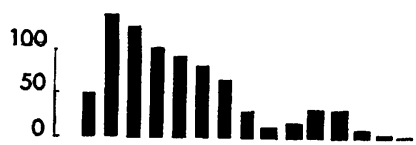

15

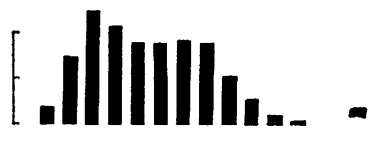

$\begin{array}{llllllll}2 & 4 & 6 & 8 & 10 & 12 & 14 & 16\end{array}$

DIAMETER $(\mu)$

FIG. 9. Distribution of diameters of myelinated fibres of the 3rd digital nerve of the hand, and of the nerve to extensor digitorum brevis in three recovering baboons. Figures on the ordinate are fibres per sq $\mathrm{mm}$ for the former, and total number of fibres for the latter nerve.

cells. In this particular nerve there were six lengths of remyelination of over one millimetre, each made up of four remyelinated segments, suggesting that a whole internode had been replaced. This is a higher incidence of segmental demyelination than was seen in any other nerve. In most cases, demyelination of a whole internodal segment was an exceptional finding.
In addition to the intercalated segments described above, short paranodal defects in myelin were seen which appeared to have been repaired by extension of myelin from an existing internode. Examples are shown in Fig. 10. These changes were more easily recognized during the early stages of recovery, and appeared to be less frequent in those animals which had been allowed to recover for long periods, sug- 
gesting that the paranodal areas could resume a normal appearance. Changes similar to those of Fig. 10 have been illustrated by Thomas and Lascelles (1966) in human diabetic neuropathy (cf. their Figs. 17b and c). The shortest intercalated segment seen in any nerve was $20 \mu$. Defects shorter than this were apparently repaired by extension of myelin from a neighbouring internode.

\section{DISCUSSION}

In the present study, and in that of Fullerton and Barnes (1966) on rats, it seems likely that the peripheral nerve damage caused by acrylamide was sufficiently severe to account for the clinical features shown by the baboons, without it being necessary to postulate an additional central effect of the toxin. In man, however, there are some features of acrylamide poisoning which cannot be accounted for on the basis of a peripheral neuropathy alone. Garland and Patterson (1967), for example, described one patient with marked truncal ataxia but without impairment of postural sense; it seems likely that in this patient some central lesion existed as well.

The findings in B18 of the present study are of interest from this point of view. This animal was given a higher dose than the others, and developed early physical signs, being tetraplegic by the 29th day. The histological changes in the peripheral nerves of this baboon, although similar in type to those found in other animals, were much less extensive, and loss of large-diameter fibres was not clearly shown. Furthermore, motor conduction velocity in the median and anterior tibial nerves and the amplitude of the muscle action potentials were normal when the animal was tetraplegic (Gilliatt and Hopkins, unpublished). This combination of findings makes it likely that some damage to the central nervous system had also occurred. Prineas (1969b), in a recent electron microscopic study of acrylamide intoxication in the cat, has found abnormalities in the spinal cord. He illustrates collections of excessive numbers of neurofilaments and of mitochondria in small myelinated fibres in the gracile nucleus, and of in the anterior spinal grey matter of the first sacral segment. A proportion of boutons terminaux in the same areas was also degenerate.

In the peripheral nerves there is no doubt that axonal degeneration is the most common pathological change. In the present study, the process. appeared to be similar to the Wallerian degeneration $\Rightarrow$ which occurs below a crush or section of a peripheral nerve (Ranvier, 1878; Ramón y Cajal, 1928). However, the electron microscopic study by Prineas (1969b) has made it clear that the axonal changes in acrylamide poisoning are different. He described, in $\stackrel{\mathbb{}}{\circ}$ the cat, increased number of neurofilaments, and $\$$ occasional complex in-foldings of the inner myelin $\vec{\circ}$ lamellae. These changes differ not only from the changes after nerve crush (Nathaniel and Pease, $\vec{\omega}$ 1963) but also from those seen in the 'dying-back' neuropathy due to tri-ortho-cresyl phosphate (Bischoff, 1967; Prineas, 1969a).

Pleasure, Mishler, and Engel (1969) have recently provided elegant support for the hypothesis that dying-back of an axon may be due to biochemicgio or changes in the cell body. These workers estimated the rate of flow of newly synthesized protein along the axon, using tritiated L-leucine as a marker. I normal cats peak radioactivity moved away from tie cord and dorsal root ganglia in the roots at the rafe $\Phi$ of about $1 \frac{1}{2} \mathrm{~mm}$ each day, whereas in cats intoxicated with acrylamide, maximal radioactivity remain adjacent to the cord and ganglia. Disturbances axoplasmic transport of protein or other substances $O$ may thus explain why the distal parts of long fibres should be first affected in an acrylamide neuropathy.

In our recovering animals there were many examples of paranodal remyelination. These were seen in some fibres at nodes immediately above the level of degeneration, but more commonly they were found in fibres with normal nodes and inte rnodesō

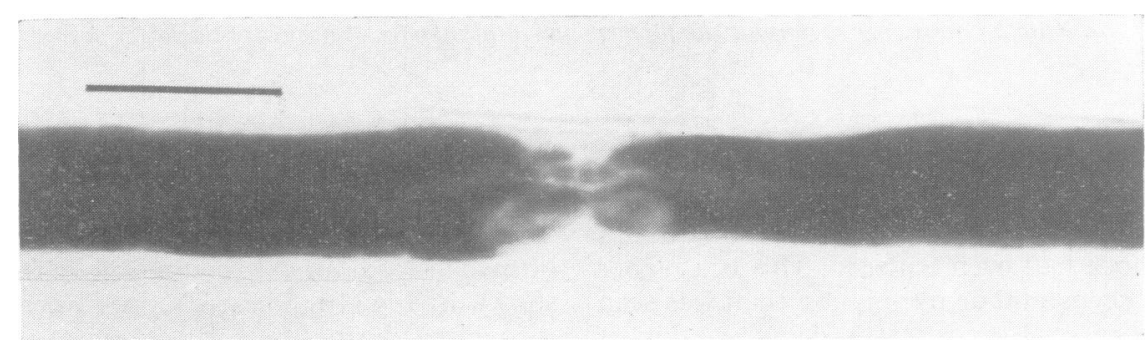

FIG. 10. Repair of defect in paranodal myelin without intercalation of a new internode. $B 15$, day 206, osmium tetroxide. Scale-20 $\mu$. 
distal to them. As it is not possible to examine more than about $10 \mathrm{~mm}$ of a single fibre, it is not possible to say whether these latter fibres were also degenerating distally. However, there is no doubt that deand remyelinated lengths could be found with up to $1 \mathrm{~cm}$ of normal nerve distal to them. This distribution differs from that of the intercalated segments described by Ranvier (1878) and Lubińska (1961), since these were limited to the two or three nodes immediately above a crush. Demyelination occurring proximal to the level of complete degeneration has been observed in patients with beri-beri (DennyBrown, 1958). It therefore seems that in certain diseases in which there is distal degeneration of peripheral nerves, there is a tendency for demyelination to occur in the proximal parts of the same nerves. In the present study demyelination was confined to the region of the nodes and only rarely extended to involve a complete internodal segment. Sometimes it produced a defect which could be repaired by extension of existing myelin; in other cases a new intercalated segment would be formed.

The cause of paranodal demyelination is obscure. Fullerton and Barnes (1966) did not observe it in the rat, although Morgan-Hughes (1970) reports it in rats of a different strain. It was not noted by Prineas (1969b) in the cat. Acrylamide could, in some species, have a direct effect on the metabolism of Schwann cells. However, as demyelination can sometimes be shown to occur proximally on fibres which are degenerating distally (v. supra), and as it does not occur as far proximally as the spinal roots, it seems more likely that it is a secondary effect of some physical or chemical change in the axon which precedes complete degeneration. If this explanation is correct, one might expect to find some demyelination in other neuropathies in which the 'dying-back' process occurs.

The fact that gross degenerative changes were confined to the distal parts of the nerves probably explains the good recovery both of function and of fibre diameter in the present study. This point will be discussed in more detail in relation to the electrophysiological findings (Gilliatt and Hopkins, 1970), but from the histological findings alone it appears that within two years of a severe neuropathy of this type, it is possible for the total fibre content and the fibre density of peripheral nerves to return to normal and for the external diameter of remyelinated and regenerated fibres to recover to approximately twothirds of normal.

This result may be compared with the findings of Fullerton (1969) who studied nerve biopsies from two factory workers, two-and-a-half and eight months after occupational exposure to acrylamide. These patients had relatively mild neurological symptoms. A transverse section of the sural nerve of one patient showed a reduction in the density of large-diameter fibres. Among the teased fibres from both patients were some which showed the characteristic features of regeneration-that is, a diameter greater than $8 \mu$ and an internodal length of less than $0.5 \mathrm{~mm}$. The fact that these were present in one patient only two-and-a-half months after withdrawal from exposure suggests that in this case regeneration had commenced while exposure continued. In the present study the 'dying-back' process was, of course, much more severe than in Fullerton's patients, and regeneration was correspondingly delayed.

This work was carried out with a grant from the Medical Research Council which is gratefully acknowledged. I thank Professor R. W. Gilliatt for his constant help and encouragement, and Dr. W. I. McDonald for help with the silver preparations.

\section{REFERENCES}

Bischoff, A. (1967). The ultrastructure of tri-ortho-cresyl phosphate poisoning. I. Studies on myelin and axonal changes in the sciatic nerve. Acta neuropath. (Berl.), 9, 158-174.

Ramón y Cajal, S. (1928). Degeneration and Regeneration of the Nervous System. Oxford University Press: London.

Denny-Brown, D. (1958). The neurological aspects of thiamine deficiency. Fed. Proc., 17, Suppl. No. 2, pp. 35-39.

Fullerton, P. M. (1969). Electrophysiological and histological observations on peripheral nerves in acrylamide poisoning in man. J. Neurol. Neurosurg. Psychiat., 32, 186-192.

Fullerton, P. M., Gilliatt, R. W., Lascelles, R. G., and Morgan-Hughes, J. A. (1965). The relation between fibre diameter and internodal length in chronic neuropathy. J. Physiol. (Lond.), 178, 26-28P.

Fullerton, P. M., and Barnes, J. M. (1966). Peripheral neuropathy in rats produced by acrylamide. Brit. J. industr. Med., 23, 210-221.

Garland, T. O., and Patterson, M. W. H. (1967). Six cases of acrylamide poisoning. Brit. med. J., 4, 134-138.

Gutmann, E., and Sanders, F. K. (1943). Recovery of fibre numbers and diameters in the regeneration of peripheral nerves. J. Physiol. (Lond.), 101, 489-518.

Hopkins, A. P. (1968). Experimental neuropathy in the baboon. M.D. Thesis: University of London.

Kuperman, A. S. (1958). Effects of acrylamide on the central nervous system of the cat. J. Pharmacol. exp. Ther., 123, 180-192.

Lubińska, L. (1961). Demyelination and remyelination in the proximal parts of regenerating nerve fibres. J. comp. Neurol., 117, 275-289.

McCollister, D. D., Oyen, F., and Rowe, V. K. (1964). Toxicology of acrylamide. Toxicol. appl. Pharmacol., 6, $172-181$.

McDonald, W. I. (1963). The effects of experimental demyelination on conduction in peripheral nerve: a histological and electrophysiological study. I. Clinical and histological observations. Brain, 86, 481-500.

Morgan-Hughes, J. A. (1970). Personal communication. 
Nathaniel, E. J. H., and Pease, D. C. (1963). Degenerative changes in rat dorsal roots during Walerian degeneration. J. Ultrastruct. Res., 9, 511-532.

Pleasure, D. E., Mishler, K. C., and Engel, W. K. (1969). Axonal transport of proteins in experimental neuropathies. Science, 166, 524-525.

Prineas, J. (1969a). The pathogenesis of dying-back polyneuropathies. Part I. An ultrastructural study of experimental tri-ortho-cresyl phosphate intoxication in the cat. J. Neuropath. exp. Neurol., 28, 571-597.

Prineas, J. (1969b). The pathogenesis of dying-back polyneuropathies. Part II. An ultrastructural study of experimental acrylamide intoxication in the cat. $J$. Neuropath. exp. Neurol., 28, 598-621.
Ranvier, M. L. (1878). Lecons sur l'Histologie du Systéme Nerveux. F. Savy: Paris.

Swallow, M. (1966). Fibre size and content of the anterior tibial nerve of the foot. J. Neurol. Neurosurg. Psychiat., 29, 205-213.

Thomas, P. K. (1955). Growth changes in the myelin sheath of peripheral nerve fibres in fishes. Proc. roy. Soc. $B$, 143, 380-391.

Thomas, P. K., and Lascelles, R. G. (1966). The pathology of diabetic neuropathy. Quart. J. Med., 35, 489-509.

Vizoso, A. D., and Young, J. E. (1948). Internode length and fibre diameter in developing and regenerating nerves. 0 J. Anat. (Lond.), 82, 110-134.

\section{The October 1970 Issue THE OCTOBER 1970 ISSUE CONTAINS THE FOLLOWING PAPERS}

Karl Friedrich Burdach and his place in the history of neuroanatomy ALFRED MEYER

Differences in recruitment order of motor units in phasic and tonic flexion reflex in 'spinal man' LENNART GRIMBY and JAN HANNERZ

Demonstration of axon reflexes in human motor nerve fibres E. STÅLBERG and J. V. TRONTELJ

Effects of botulinum toxin on the distribution of succinate dehydrogenase and phosphorylase in fast and slow skeletal muscles of the mouse $\mathbf{L}$. W. DUCHEN

Pathology of the peripheral nerves in leprosy: report of a case A. D. DAYAN and U. SANDBANK

Rheumatoid neuropathy: a histological and electrophysiological study R. O. WELLER, F. E. BRUCKNER, and M. ANNE CHAMBERLAIN

Schwann cell dysfunction in uraemia J. J. DINN and D. L. CRANE

Peripheral nerve function in chronic liver disease $\mathrm{K}$. N. SENEVIRATNE and 0 . A. PEIRIS

Wasting of the hand associated with a cervical rib or band R. W. GILLIATT, PAMELA M. LE QUESNE, VALENTINE LOGUE, and A. J. SUMNER

Rate of recovery in motor and sensory fibres of the radial nerve: clinical and electrophysiological aspects $w$. TROJABORG

Ocular myasthenia: evaluation of Tensilon tonography and electronystagmography as diagnostic tests $\mathbf{M}$. J. CAMPBELL, E. SIMPSON, A. L. CROMBIE, and J. N. WALTON

Report of 10 operations under local cerebral hypothermia BERNARD N. WILLIAMS and ERIC A. TURNER
Acquired hepatocerebral degeneration: report of an atypical case D. I. GRAHAM, J. HUME ADAMS, F. I. CAIRD, and JOHAN W. LAWSON

Controlled trial of hydroxocobalamin and riboflavine ō c Nigerian ataxic neuropathy B. o. osunToKúN, M. J. LANGMAN, J. WILSON, and A. ALADETOYINBO

Subacute necrotizing encephalomyelopathy. Its relation: ship to central pontine myelinolysis AMIN A. FARIS ant $\overparen{D}$ LORAN D. FLECKENSTEIN

Nishimoto-Takeuchi-Kudo disease: case report URBÁNEK, H. FÁRKOVÁ, and E. KLAUS

Artificial embolization of carotid-cavernous fistula with post-operative patency of internal carotid artery FABIAN. ISAMAT, V. SALLERAS, and A. M. MIRANDA

Abnormal brain scan with subacute extradural haematomas J. BARRIE MORLEY and KEITH H. LANGFORD

Familial centronuclear myopathy w. G. BRADLEY, D. L. PRICE, and C. $K$. WATANABE

Quantitative immunoelectrophoresis of serum from $\overrightarrow{\vec{D}}$ hospitalized chronic schizophrenic and epileptic patients H. G. MINCHIN CLARKE, T. FREEMAN, and W. PRYSEPHILLIPS

Tryptophan metabolism in depression G. CURzoN and P. K. BRIDGES

Unilateral and bilateral ECT: a study of memory disturbance and relief from depression D. CRONIN, P. 3 BODLEY, L. POTTS, MARCIA D. MATHER, R. K. GARDNER, and JEAN C. TOBIN

Proceedings of the Society of British Neurological Surgeons

Book reviews

Copies are still available from the PUBLISHING MANAGER, BRITISH MEDICAL ASSOCIATION, TAVISTOCK SQUARE, LONDON, WC1H 9JR, price $21 s$. 